\title{
Multidimensional Adaptive Teaching Model Based on Bidirectional Feedback
}

\author{
Zhao Xia ${ }^{1,2}$, Lin Tian-hua ${ }^{2}$, Huo Zheng ${ }^{2}$, Jiang Jian-wei ${ }^{2}$ \\ ${ }^{1}$ Economics and Management Experimental Center, Hebei University of Economics and Business, Shijiazhuang, China \\ ${ }^{2}$ Information Technology College, Hebei University of Economics and Business, Shijiazhuang, China
}

\section{Email address:}

piaoxuexiaoyao@126.com (Zhao Xia), linagel180@163.net (Lin Tian-hua),31841415@qq.com (Huo Zheng),

1578541568@qq.com (Jiang Jian-wei)

\section{To cite this article:}

Zhao Xia, Lin Tian-hua, Huo Zheng, Jiang Jian-wei. Multidimensional Adaptive Teaching Model Based on Bidirectional Feedback. Science Innovation. Vol. 6, No. 1, 2018, pp. 28-32. doi: 10.11648/j.si.20180601.17

Received: February 1, 2018; Accepted: March 29, 2018; Published: May 23, 2018

\begin{abstract}
Through practice and exploration, a multidimensional adaptive teaching model is proposed based on good feedback between students and teachers. Firstly, this paper expounds the connotation of the model includes bidirectional feedback, multiple dimensions and adaptability. Then the implementation conditions of the model are analyzed from objective and subjective aspects. Then the implementation process of the model is described in detail by the course of SCM (Single chip Microcomputer, SMC) theory and its application. Finally, the model is evaluated by questionnaire and achievement of teachers and students.
\end{abstract}

Keywords: Bidirectional Feedback, Multiple Dimensions, Adaptability, Interaction Between Teachers and Students, Education Reform

\section{基于双向反馈的多维自适应教学模式}

\author{
赵霞 ${ }^{1,2}$, 林天华 ${ }^{2}$, 霍峥 $^{2}$, 蒋建伟 ${ }^{2}$ \\ 1经济管理实验中心, 河北经贸大学, 石家庄, 中国 \\ 2 信息技术学院, 河北经贸大学, 石家庄, 中国
}

\section{邮箱}

piaoxuexiaoyao@126.com (赵霞)，linagel180@163.net（林天华）, 31841415@qq.com（霍峥）, 1578541568@qq.com（蒋建伟）

摘要: 经过不断的实践, 基于学生和教师之间的良好反馈机制, 提出了一种多维度的, 具有自适应性的教学模式。首 先, 从双向反馈、多维度、自适应性三个方面, 阐述该教学模式的内涵。其次, 通过客观和主观分析, 阐明了实施该 模式的具体条件。然后, 以《单片机原理及应用》这门课程为例, 详细描述了该模式的实施过程。最后, 通过调查问 卷、师生成绩等方法说明该教学模式的效果得到学生和相关管理者的认可。

关键词: 双向反馈, 多维度, 自适应性, 师生互动, 教学改革 


\section{1. 引言}

信息时代的教学过程相比传统的教学过程有很多不 同, 如网络教学资源对传统课堂的冲击, 学生碎片化学习 习惯的养成等。在这种形势下, “老师台上讲, 学生台下 听”的教学模式显然不能满足学生的需求。为了面对新形 势下的教学挑战, 传统教学模式亟需变革。

何朝阳等分析了迈阿密大学等美国高校进行翻转 课堂的教育过程, 指出了翻转课堂教学模式的优势 [1]。 李红美等针对在线教育中教与学的时空模式, 构建了基 于“教学环境-教学响应”视角的 CH-SPOC教学模式, 并 以浙江大学为例, 展示了教学新模式的实践及应用 [2]。 邢以群等提出了以学生为中心的体验式教学模式, 并对 其内涵、实施路径、方法和效果进行了系统探讨和分析 [3]。朱红等介绍了北京大学推行的"大班授课, 小班讨 论”的教学模式, 充分利用大小班结合的特点, 提高了 学生的参与度, 促进了师生互动和生生互动 [4]。黄海风 等推出了以SPOC (Small Private Online Course, SPOC) 为核心的混合教学模式, 即可以充分利用 $\mathrm{MOOC}$

(Massive Open Online Course, MOOC) 的优质教学资 源, 又可以发挥传统课堂上师生面对面交流的优势, 提 高学生的学习积极性[5]。贾国瑞等提出了课堂教学与网 络教学相结合的方法, 突出学生在教学中的主体地位 [6]。 徐敬青等利用“师生共讲”的教学模式, 提高了学生的学 习积极性 [7]。黄震阐述了“互联网+”时代, 上海交大在 MOOC和混合式教学方面的探索与实践 [8]。吴金旺等介 绍了信息时代高职院校的课堂教学创新体系, 该创新体 系包括了教与学的氛围营造、教与学的过程创新及评价 反馈机制创新 [9]。刘刚等阐述了在互联网+时代, 高校 教学创新需要学校、教师和学生三方面的共同努力[10]。 由此可见, 高校在新形势下的教学改革和创新势在必行。

作为高校教师, 课题组人员长期从事计算机专业领域 的教学和科研工作。经过不断的尝试和总结, 多次的讨论 和归纳, 课程组人员摸索出一种适于应用类课程的教学模 式---基于双向反馈的多维自适应教学模式。将该教学模式 应用于日常授课中, 获得了理想的教学效果。

\section{2. 该教学模式的内涵}

该教学模式的重点内容有三个, 分别是双向反馈、多 维性和自适应性。下面就从这三个方面介绍该模式的内涵。

\section{1. 双向反馈}

是指教师与学生之间的双向反馈。学生可以反馈信息 给教师, 教师反馈信息给学生这样的一个双向反馈过程。

反馈形式主要包括：（1）提问：包括传统意义上 的课堂提问, 也包括虚拟课堂中的提问。问题的发起者, 可以是教师也可以是学生。教师随机提问学生, 检查学 生知识掌握的情况。学生向教师提问, 解决不理解的问 题。（2）作业: 在完成每章或每个模块的学习后, 教 师布置作业供学生巩固提高课堂知识。学生独立完成作 业将自己掌握知识的情况反馈给教师。（3）实验：学 生理解、巩固课堂知识的必要手段, 也是锻炼学生工程
实践能力的重要途径。教师通过设计实验内容, 全面考 查学生对知识的掌握情况。学生通过做实验, 不断的发 现问题、解决问题, 提高综合运用知识的能力。 答疑: 摆脱传统课堂的时空限制, 充分利用网络平台及 社交工具, 由学生主动提出问题, 教师给予解答, 并组 织深入讨论, 完成学生和教师之间的双向反馈。(5) 测验: 学生通过参加考试或测验展示自己的真实水平, 教师通过阅卷发现学生存在的问题, 并通过分析试卷将 学生中普遍存在的问题反馈给学生。

\section{2. 多维度}

在该模式中, 多维性主要体现在如下 5 个方面, 分别 为教学环境、教学内容、教学形式、教学手段、教学评价。

\subsection{1. 教学环境多维}

就教学地点来说, 教师可以采用传统的教室、实验室 进行教学, 也可以通过MOOC平台、虚拟课堂等网络方式 进行教学。就教学工具来说, 教师可以通过 $Q Q$ 、微信等 社交软件发布课程相关的资料, 回答学生的问题, 为课堂 教学提供辅助性支撑。

\subsection{2. 教学内容多维}

对于课本知识, 教师需对教学内容进行模块化设计, 在每个教学模块内进行层次化设计, 理清该模块的基础知 识, 重难点和扩展知识, 打造课程内知识的横向和纵向两 个维度。对于课程相关知识, 明确先修课程, 后续课程的 主线, 帮助学生理解知识脉络。

\subsection{3. 教学形式多维}

课堂上, 除了教师讲授外, 充分利用提问, 讨论, 演 示等环节, 调动学生的学习积极性, 打造“合作、探究”的 学习氛围。

\subsection{4. 教学手段多维}

在课堂讲授中, 教师充分利用课件、动画、视频等素 材, 力求将抽象知识形象化。课外充分利用MOOC资源, 名校网络公开课等相关教学资源进行辅助性教学。

\subsection{5. 教学评价多维}

该教学模式可以从学生和管理者两个角度进行评价。 评价内容从授课过程、授课教师、教学效果等维度进行评 价。

\section{3. 自适应性}

建立良好的师生反馈机制后, 教师要具备对学生反馈 信息的洞察力, 对课堂组织的掌控力, 对课堂情况的适应 力, 对授课过程、授课方法和授课形式等及时调整, 适应 学生的学习状态。具体来说, 教师不应盲目追求完成教学 任务, 而忽略教学效果的提升。对于提问、作业等辅助环 节, 需要根据授课班级学生的基础、领悟程度等及时调整, 而不能按惯性思维对每一届学生, 每一班学生采用同一个 作业或问题。对于课堂的组织形式, 也应该根据学生的情 况, 采用授课、讨论等形式, 适于学生当前的学习状态。 


\section{3. 该教学模式实施的条件}

\section{1. 基础软硬件设施}

学校在教学区、办公区、宿舍区等布设流畅的有线或 无线网络, 这是采取网络教学的基础保障, 也是采用 $\mathrm{QQ}$ 、 微信等网络交流方式进行双向反馈的前提条件; 授课教室 具备多媒体教学系统, 方便教师和学生演示与课程相关的 课件、图片、视频等内容; 学校提供必要的在线教学管理 平台（如Blackboard平台）, 供师生共建网络课堂。

\section{2. 政策支持}

\subsection{1. 学校对课堂教学改革的持续投入}

该教学模式中, 要求教师尽量全面掌握学生的作业、 提问等反馈信息, 要求教师不断探索具体知识点的最佳教 学方法, 在教学理念上不断创新, 这些工作繁琐且任务量 大, 需要教师投入很多的时间和精力。为此, 学校应该制 定相关的措施, 引导教师敢于尝试教学改革, 并能够对教 学改革保持较高的热情。

\subsection{2. 教学管理策略的创新}

现有的教学管理部门是以教学任务、教学进度表、教 学大纲等为基础进行期初、期中、期末检查, 这是教学管 理的规范化流程。本文所述教学模式下: 教师的授课理念 是以传授知识为载体, 以教会学生“如何分析问题, 解决 问题”为重点; 授课内容是取课程的核心内容进行精讲, 对细节性内容可以“边用边学”; 在教学方法和手段上也要 大胆创新。所以, 教学管理部门可以探索对教学过程可控, 但给予教师更多创新空间的管理策略。

\subsection{3. 小班教学的保证}

本教学模式的基础是教师要通过反馈机制及时掌握 每个学生的情况。对于教师来说, 大班教学, 教师受限于 时间和精力, 不能及时掌握每个学生的学习情况。小班教 学便于教师掌握学生的情况, 学生也有足够的机会展示自 己的能力水平。

\section{4. 该教学模式的实施过程}

该教学模式适用于应用性较强的课程, 下面以《单片 机原理及应用》这门课程为例, 讲述该教学模式的实施过 程。

\section{1. 信息通路的搭建}

教师利用BlackBoard平台创建网络课堂。在网络课堂 上提供该课程的全部教学资源, 包括预习内容、课件、重 难点解析、作业、实验内容等, 资源形式以文档、动画、 视频等为主。除此之外, 提供公告发布, 讨论版, 虚拟课 堂等模块供师生交流。最后需要提供网络优质学习资源的 相关链接, 供学生在线学习。教师加入班级QQ群、微信, 方便教师和学生的及时沟通。

\section{2. 课程建设}

\subsection{1. 教学内容的设计}

对于应用性课程, 大多既有理论知识, 又有实验。对 于理论知识, 打破书本中的章节结构限制, 对课程的重点 内容逐个梳理, 进行模块化设计。在大模块下又细分小的 模块, 达到每次课一个知识模块的目的。理论教学进行上 述改革后, 实验教学应避免完全按照实验指导书进行的做 法, 应结合理论教学的情况及时调整每次实验的内容, 达 到“学中做, 做中学”的目的。所以, 教师在上实验课之前 需要根据上课的情况, 设计实验课的内容。为了适应不同 学生的需求, 应将实验内容划分为基础验证性内容+扩展 实验内容+设计实验内容等。

\subsection{2. 教学过程的设计}

下面从理论教学和实验教学两个方面对教学过程进 行详细介绍。

对于理论教学:每次授课过程分为预习、课堂演示、 授课、课堂练习/讨论、课后作业这几个阶段。其中预 习阶段, 教师通过BlackBoard平台发布预习内容及先修 知识。通过讨论版或社交聊天软件, 了解学生对先修知 识的掌握程度。教师根据学生的反馈情况, 决定是否需 要对先修知识中的难点内容在课堂中给予补充; 课前演 示环节每 3 周举行一次, 同学可以主动要求进行演示, 教师也可以根据学生的反馈信息指定同学进行演示。学 生演示时间一般是 5 10分钟, 演示自己作品的功能及实 现方法。教师针对学生演示的内容, 从知识原理、完成 情况、改进意见等角度进行点评。若条件允许, 可以请 同学现场改进作品。这种方法, 既提高了学生的学习积 极性, 又锻炼了学生的语言表达能力, 利于提升教学效 果; 授课过程中, 教师根据授课内容灵活采用多种教学 手段, 一般情况下, 教师运用先进的教学手段讲授课程 重点内容, 而后通过引导、启发等方法带领学生共同学 习。在这个过程中, 允许学生随时向教师提出问题, 也 允许教师随时向学生提问, 开展正常教学。对于练习及 讨论, 教师需要根据授课内容, 缩短讲授时间, 预留出 练习或讨论的时间。课后, 教师通过BB平台发布课后 作业, 作业可以针对课堂中具体知识点的题目, 也可以 是与本次课知识点相关的一个综合题目。制定好相关评 分规则后, 学生需要及时完成作业并按期上交到网络课 堂。而后教师评阅作业, 对作业中普遍存在的问题进行 归纳总结, 必要时在下次上课时进行讲解。课后, 教师 需要在网络课堂提供相关学习资料, 引领学生自主学习 更深层次的知识。由此可知, 理论授课过程是预习、上 课及复习的完整的过程, 在每个过程里面, 都注重师生 反馈。

对于实验课: 教师根据实验指导书和学生的具体学习 情况, 设计实验内容。为了层次化教学, 实验内容应该难 易有别。教师对实验内容中的关键问题进行分析, 采用启 发式教学方法带领学生解决实验中存在的关键技术问题。 学生在实验环境下自己动手, 完成实验。学生完成实验后, 教师要引导学生对实验内容进行总结。对于个性化的实验, 
教师给予备案和登记。实验课后, 学生提交实验报告, 教 师给予评阅。

在每个学期期中设置一次期中考试, 对学生的学习 情况进行摸底。在课程主要内容讲述完后, 教师需布置 一次课程设计, 考查学生对该门课程知识的综合运用能 力。

\section{3. 课程考核方法的设计}

课程考核时，注重过程化考核。平时成绩和期末考试 成绩各占总成绩的 $50 \%$ 。其中，平时成绩由考勤（10\%） +课堂提问 $(20 \%)$ +课堂讨论 $(10 \%)+$ 课后作业 $(20 \%)$ +课程设计 $(20 \%)+$ 实验 $(20 \%)+$ 课堂演示（加分项） 这几部分组成。

在授课过程中, 全员考勤设置5次, 每次考勤占考勤 成绩的 $20 \%$; 课堂提问环节, 对于教师所提问题, 鼓励学 生主动回答, 答对得分, 答错不扣分。提问过程在鼓励学 生抢答的同时, 要照顾到学生参与的普遍性, 争取每个学 生都有 1 2次回答问题的机会; 课堂讨论环节, 则根据学 生的参与度和提出问题的质量进行考核。为了保证教学进 度, 在这个环节可以设置小组讨论, 形成组长对本组成员 打分, 教师为本组学生打分的机制; 课堂作业实行学生独 立完成作业, 根据作业的正确度和完整度打分; 为了对知 识点进行综合练习, 在课程结课前需要布置课程设计。课 程设计分值由设计内容+设计报告组成。设计内容是否满 足题目要求, 是否符合逻辑要求, 设计报告撰写是否规范 等考核要求; 实验成绩由考勤+实验完成情况+实验报告三 部分组成; 课堂演示环节, 在考核中施行加分鼓励政策。 在进行时, 优先支持主动要求演示的同学, 其余同学可以 是教师根据学生的反馈信息指定。根据学生的演示情况及 回答问题情况，教师给予评分。

\section{5. 该教学模式的效果}

\section{1. 通过调查问卷了解学生的真实想法}

为了更好的了解学生对在该教学模式下的感受, 对涉 及2013 2017级300余名学生进行调查。从调查结果看, 学 生接受并认可该教学模式。

\section{2. 师生取得的相关成绩}

该教学模式实施以来, 课题组教师和学生都取得不错 的成绩。课题组老师于 2014 年获得青年教师讲课比赛一等 奖。同年, 该课程被批准为学校的精品资源共享课程。2015 年, 课题组成员获得教学优秀奖。由此可见, 该教学模式 得到教学管理部门的认可。2013 2015年, 我校数十名同 学参加全国大学生电子设计大赛, 并多次获奖。学生的学 习积极性得到提高, 学习效果也值得肯定。

\section{6. 结论}

基于双向反馈的多维自适应教学模式是“互联网+”时 代背景下, 课题组人员在教学内容、教学手段、教学组织 上的一次创新过程。该教学模式需要师生之间的良好互动, 这是双向反馈的基础。该教学模式对教师的课程设计能力、 课堂组织能力等均提出了新的要求。通过近 3 年的努力探 索及相应的效果评价, 该教学模式得到了学生和相关管理 部门的认可, 在同类院校的相似课程中值得推广。

\section{致谢}

本文为河北经贸大学精品资源共享课 (单片机原理与 应用），河北经贸大学教改项目（2017JYY70）的阶段性 成果之一。

\section{参考文献}

[1] 何朝阳, 欧玉芳, 曹祁。美国大学翻转课堂教学模式的启 示 $[J]$ 。高等工程教育研究, 2014(2):148-151。

[2] 李红美, 陆国栋, 张剑平.后MOOC时期高等学校教学新模 式探索[J]。高等工程教育研究, 2014(6):58-67。

[3] 邢以群, 鲁柏祥, 施杰, 等。以学生为主体的体验式教学 模式探索—从知识到智慧 $[\mathrm{J}]$ 。高等工程教育研究, 2016(5):122-128。

[4] 朱红, 马莉萍,熊显。“大班授课、小班研讨”教学模式效果 研究[J].中国高教研究, 2016(01):42-47。

[5] 黄海风, 刘培国, 唐波, et al.SPOC: 高校混合教学新模式 [J]。高等教育研究学报, 2016(02):43-48。

[6] 贾国瑞, 赵慧洁, 郭琦, et al.网络教学融入高校工科专业 基础课的实践——以光电子技术”课程为例 [J]。高等教育 研究学报, 2016(01):96-100。

[7] 徐敬青, 范志锋, 崔平, et al.“师生共讲”教学模式研究与 实践 $[J]$ 。高等教育研究学报,2016(01):106-110。

[8] 黄震。基于慕课和混合式教学的工程教育探索与实践 $[\mathrm{J}]$ 。 高等工程教育研究, 2016(04):11-13。

[9] 吴金旺, 郭福春。信息技术环境下财经类高职院校课堂教 学创新体系探索 [J]。高等工程教育研究, 2016(04):151-154。

[10] 刘刚, 李佳, 梁晗。“互联网+”时代高校教学创新的思考与 对策[J]。中国高教研究, 2017(2):93-98。 


\section{作者简介}

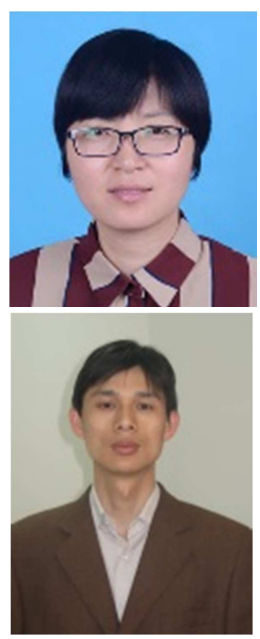

赵霞 (1979-), 女, 河北定州人, 副 教授, 博士, 主要从事计算机方面的 教学与研究工作。

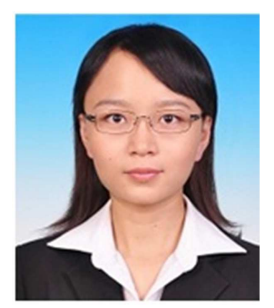

霍峥 (1982-), 女, 讲师, 博士, 主 要从事计算机方面的教学与研究工 作。

林天华（通讯作者），(1979-)，男， 福建上杭人, 副教授, 主要从事计算 机方面的教研工作。

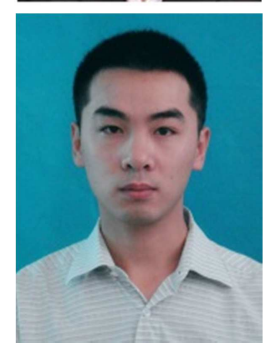

蒋建伟（1980-)，男，讲师，硕士， 主要从事计算机方面的教学与研究工 作。 